\title{
An oncogenic function of retinoic acid receptor- $\alpha$ in the development of laryngeal squamous cell carcinoma
}

\author{
CHENG-FU CAI ${ }^{1}$, CUN-SHAN LIU ${ }^{1}$, HAN-JING SHANG-GUAN ${ }^{1}$, CAI-HONG YANG ${ }^{1}$, \\ XIAN-YANG LUO ${ }^{1}$, DONG-YAN SHEN ${ }^{2}$ and SHU-YU YANG ${ }^{3}$ \\ ${ }^{1}$ Department of Otorhinolaryngology, Head and Neck Surgery; ${ }^{2}$ Biobank; ${ }^{3}$ Xiamen Diabetes Institute, \\ The First Affiliated Hospital of Xiamen University, Xiamen, Fujian 361003, P.R. China
}

Received May 22, 2016; Accepted September 1, 2017

DOI: 10.3892/ol.2017.7194

\begin{abstract}
The aberrant expression of retinoic acid receptor- $\alpha$ $(\operatorname{RAR} \alpha)$ has been reported in various types of cancer. However, its association with the prognosis and development of laryngeal squamous cell carcinoma (LSCC) has not yet been determined. Therefore, the present study aimed to examine the expression and function of RAR $\alpha$ in patients with LSCC. The expression of RAR $\alpha$ in LSCC tissues was investigated using immunostaining. An MTT assay and flow cytometry analysis were also performed to investigate the function of RAR $\alpha$ in the proliferation and cell cycle of LSCC cells. The expression of RAR $\alpha$ was significantly elevated in LSCC tissues compared with adjacent noncancerous tissues (78.1 vs. $6.3 \%$, $\mathrm{P}<0.05)$. The overexpression of $\operatorname{RAR} \alpha$ was associated with poorly differentiated features of $\operatorname{LSCC}(\mathrm{P}<0.05)$. Furthermore, the downregulation of RAR $\alpha$ inhibited the proliferation of LSCC cells, and arrested the cell cycle at the G1 phase via upregulation of cyclin dependent kinase inhibitor 1A, which may be associated with inhibition of the protein kinase $B$ signaling pathway. Therefore, the overexpression of RAR $\alpha$ may contribute to the development of LSCC through the regulation of the cell cycle. The results of the present study provide evidence that $\mathrm{RAR} \alpha$ serves an important function in LSCC development and may be a potential therapeutic target or prognostic predictor for LSCC.
\end{abstract}

Correspondence to: Dr Dong-Yan Shen, Biobank, The First Affiliated Hospital of Xiamen University, 55 Zhenhai Road, Xiamen, Fujian 361003, P.R. China

E-mail: shendongyan@163.com

Dr Shu-Yu Yang, Xiamen Diabetes Institute, The First Affiliated Hospital of Xiamen University, 55 Zhenhai Road, Xiamen, Fujian 361003, P.R. China

E-mail: yangshuyu2016@163.com

Key words: retinoic acid receptor- $\alpha$, laryngeal squamous cell carcinoma, proliferation, cell cycle

\section{Introduction}

Laryngeal carcinoma, of which $>95 \%$ of cases are laryngeal squamous cell carcinoma (LSCC), is a prevalent malignancy of the head and neck, with an incidence of 3.5-5.5/100,000 people and a mortality rate of 2.1-2.4 per 100,000 people worldwide in $2008(1,2)$. Although there have been significant improvements in terms of diagnosis and treatment, the clinical outcome of therapy for patients with LSCC, particularly those with advanced stages of the disease, remains poor (3). Therefore, it is necessary to explore the molecular mechanisms of LSCC, which will contribute to increasing survival rates and improving prognosis.

Previous studies have revealed that retinoic acid receptors (RARs) serve important functions in various types of cancer (4). The RAR family contains three different subtypes (namely, RAR $\alpha$, RAR $\beta$ and RAR $\gamma$ ). As RARs are important members of the nuclear receptor superfamily, the three subtypes function as transcription factors that are essential in embryonic development, the maintenance of differentiated cellular phenotypes, metabolism and cell death (5). The three RAR subtypes are encoded by different genes and they differ in terms of structure and distribution as well as possessing unique functions. Increasingly, the evidence has indicated that the aberrant expression of RAR $\alpha$ is present in various types of cancer. RAR $\alpha$ was revealed to regulate the cell differentiation of neurocytoma through the activation of the transcription of associated target genes (6). The activation of RAR $\alpha$ competed with the fusion protein promyelocytic leukemia gene-RAR $\alpha$, induced by a mutation to combine with the Fas cell surface death receptor domain structure, promoting the apoptosis of myeloid leukemia (7). The activation of RAR $\alpha$ also promoted cell cycle arrest and the apoptotic process in lymphoma cells through the upregulation of reactive oxygen species (8). The protein stability of RAR $\alpha$, enhanced by ubiquitin, inhibited the proliferation of gastric cancer cells (9). The contribution of RAR $\alpha$ to the development of hepatocellular carcinoma was associated with its regulation of cytochrome P450 family 1 subfamily A member 1 expression $(10,11)$. RAR $\alpha$ is also involved in the development of breast cancer and prostate carcinoma (12-14). However, little is known about the expression and function of RAR $\alpha$ in human LSCC. 
In the present study, the function and mechanisms of RAR $\alpha$ in primary LSCC tissues and adjacent normal tissues were investigated. It was revealed that the overexpression of RAR $\alpha$ in LSCC tissues promoted the proliferation of leukocyte common antigen (LCA) cells through the regulation of the cell cycle, with definitive clinical significance. The results of the present study may provide a reference to gain additional insight into the potential function of RAR $\alpha$ in the development of LCA, suggesting a potential target for LSCC therapy.

\section{Materials and methods}

Patients and tissue samples. Fresh human laryngeal carcinoma and adjacent noncancerous tissues were obtained from 32 patients who underwent surgery at the First Affiliated Hospital of Xiamen University (Xiamen, China). Tumor tissues and adjacent non-tumor tissues were sampled and immediately soaked in formalin overnight, and then paraffin embedded. The pathological characteristics were confirmed by pathological examination. The present study was approved by the ethics committee of the First Affiliated Hospital of Xiamen University, and all patients provided written informed consent prior to participation. None of the patients with LSCC were treated with radiotherapy, chemotherapy or other types of therapy prior to surgery. Metastatic tumors from other tissues were excluded from the study. The clinicopathological characteristics are presented in Table I.

Cell culture. The LSCC cell line AMC-HN-8 purchased from the Cell Bank of Type Culture Collection of Chinese Academy of Science (Shanghai, China). Cells were cultured in RPMI-1640 medium (Gibco; Thermo Fisher Scientific, Inc., Waltham, MA, USA) supplemented with $10 \%$ fetal bovine serum (FBS; Hyclone; GE Healthcare Life Sciences, Logan, UT, USA) and antibiotics (100 U/ml penicillin and $100 \mathrm{mg} / \mathrm{ml}$ streptomycin) at $37^{\circ} \mathrm{C}$ in a humidified atmosphere of $5 \% \mathrm{CO}_{2}$.

Cell transfection. RAR $\alpha$-specific small interfering (si)RNA ( $\operatorname{siRAR} \alpha$ ), 5'-AUCUCUUCAGAACUGCUGCUCUGGG-3' and the Stealth RNAi ${ }^{\text {TM }}$ siRNA negative control (siCtrl), 5'-UAU CCUUACGAGUACCUUGCGGCUG-3' were designed and obtained from Invitrogen; Thermo Fisher Scientific, Inc. LSCC cells were seeded in 6 well plates at a density of $0.5 \times 10^{6}$ cells per well. siRAR $\alpha$ and siCtrl were transfected into cells using the LipoRNAiMAX transfection reagent (Invitrogen; Thermo Fisher Scientific, Inc.), according to the manufacturer's protocol. Following transfection at $37^{\circ} \mathrm{C}$ in a humidified atmosphere with $5 \% \mathrm{CO}_{2}$ for $24 \mathrm{~h}$, cells were collected for subsequent experiments.

Cell proliferation assay. Cell proliferation was analyzed using an MTT assay (Sigma-Aldrich; Merck KGaA, Darmstadt, Germany). The cells were seeded at a density of $5 \times 10^{3}$ cells per well into 96-well plates overnight. Following the transfection of cells with siRAR $\alpha$ and siCtrl, $20 \mu 1$ MTT (5 mg/ml) was added to each well, and the cells were cultured for a further $4 \mathrm{~h}$ at $37^{\circ} \mathrm{C}$. Then the formazan crystals formed were dissolved in DMSO. The absorbance was measured at $490 \mathrm{~nm}$ using an ELISA microplate reader. All experiments were performed in triplicate.
Table I. Associations between RAR $\alpha$ and clinical features of laryngeal squamous cell carcinoma.

\begin{tabular}{|c|c|c|c|c|c|}
\hline \multirow[b]{2}{*}{ Features } & \multirow[b]{2}{*}{$\mathrm{N}$} & \multicolumn{2}{|c|}{$\operatorname{RAR} \alpha$} & \multirow[b]{2}{*}{$\chi^{2}$} & \multirow[b]{2}{*}{ P-value } \\
\hline & & Low & High & & \\
\hline Age, years & & & & 0.0185 & 0.8918 \\
\hline$<59$ & 13 & 3 & 10 & & \\
\hline$>60$ & 19 & 4 & 15 & & \\
\hline Sex & & & & 0.0261 & 0.8716 \\
\hline Male & 28 & 6 & 22 & & \\
\hline Female & 4 & 1 & 3 & & \\
\hline $\begin{array}{l}\text { Pathologic } \\
\text { differentiation }\end{array}$ & & & & 6.8183 & $0.0331^{\mathrm{a}}$ \\
\hline High & 14 & 6 & 8 & & \\
\hline Middle & 8 & 1 & 7 & & \\
\hline Low & 10 & 0 & 10 & & \\
\hline T stage & & & & 0.4780 & 0.9237 \\
\hline $\mathrm{T} 1$ & 7 & 1 & 6 & & \\
\hline $\mathrm{T} 2$ & 13 & 3 & 10 & & \\
\hline $\mathrm{T} 3$ & 9 & 2 & 7 & & \\
\hline $\mathrm{T} 4$ & 3 & 1 & 2 & & \\
\hline $\begin{array}{l}\text { Lymph node } \\
\text { metastasis }\end{array}$ & & & & 1.0135 & 0.3141 \\
\hline NO & 19 & 3 & 16 & & \\
\hline $\mathrm{N}+$ & 13 & 4 & 9 & & \\
\hline Distant metastasis & & & & 0.9874 & 0.3204 \\
\hline M0 & 30 & 6 & 24 & & \\
\hline $\mathrm{M}+$ & 2 & 1 & 1 & & \\
\hline Clinical stage & & & & 0.5644 & 0.9045 \\
\hline 1 & 6 & 1 & 5 & & \\
\hline 2 & 14 & 3 & 11 & & \\
\hline 3 & 11 & 3 & 8 & & \\
\hline 4 & 1 & 0 & 1 & & \\
\hline
\end{tabular}

${ }^{a} \mathrm{P}<0.05$ was considered to indicate a statistically significant difference. RAR, retinoic acid receptors.

Colony formation. A total of 600 AMC-HN-8 cells were cultured in 6-well plates for 14 days and then fixed and stained with $0.005 \%$ crystal violet for $30 \mathrm{~min}$ at room temperature. Colonies $>100 \mu \mathrm{m}$ in diameter were counted under a light microscope (Olympus BH-2, Olympus Corporation, Tokyo, Japan).

Reverse transcription quantitative RT- $(q) P C R$. Total RNA was extracted from cells using an RNA Extraction kit (cat. no. DP405-02; Tiangen, Beijing, China) according to manufacturer's protocol. Reverse transcription was carried out using the SuperScript III First-Strand Synthesis system (Invitrogen; Thermo Fisher Scientific, Inc.) for qPCR. The qPCR was carried out by ABI 7500 Fast Real-Time PCR system (Applied Biosystems; Thermo Fisher Scientific, Inc.) with SYBR-Green (Promega Corporation, Madison, WI, USA) as a fluorophore. GAPDH was used as a control. The primer sequences are listed 
Table II. Primer sequences for reverse transcription-quantitative polymerase chain reaction analysis.

\begin{tabular}{lll}
\hline Gene & \multicolumn{1}{c}{ Sense $\left(5^{\prime}-3^{\prime}\right)$} & Antisense $\left(5^{\prime}-3^{\prime}\right)$ \\
\hline RAR $\alpha$ & AATACACTACGAACAACAGC & CGAACTCCACAGTCTTAATG \\
P21 & CTAGTTCTACCTCAGGCAGCT & GTCGCTGGACGATTTGAGG \\
P27 & GTTAGCGGAGCAATGCGC & CAGGCTTCTTGGGCGTCTG \\
Cyclin A & AAGCACTCCCTGACTGTGG & ACTGATGTTCTTGGTGAC \\
Cyclin B & CCTCAACCATCCTGGCTGCG & CTGTTCTTGGCCTCAGTCC \\
Cyclin D & CCGAGTCACCAGGAACTCGA & AGGACAGACTCCGCTGTGC \\
Cyclin E & AATGTCAAGACGAAGTAGCC & ATTTCCTCAAGTTTGGCTGCA
\end{tabular}

RAR $\alpha$, retinoic acid receptor- $\alpha$; P21, cyclin dependent kinase inhibitor 1A; P27, cycin dependent kinase inhibitor $1 \mathrm{~B}$.

in Table II. All experiments were performed in triplicate, and the data were relatively calculated using the $2^{-\Delta \Delta \mathrm{Cq}}$ method (15).

Western blotting. Whole-cell lysates were prepared in lysis buffer (50 mM Tris- $\mathrm{HCl} \mathrm{pH}$ 7.5, $100 \mathrm{mM} \mathrm{NaCl,} 50 \mathrm{mM} \mathrm{NaF}$, $1 \mathrm{mM}$ Na3VO4, $30 \mathrm{mM}$ sodium pyrophosphate, 0.5\% NP-40 and $0.5 \mathrm{mM}$ PMSF (Sigma-Aldrich; Merck KGaA) supplemented with EDTA-free protease inhibitor cocktail (Roche Diagnostics, Basel, Switzerland), and insoluble debris was pelleted by centrifugation for $20 \mathrm{~min}$ at $4^{\circ} \mathrm{C}$ and $13,000 \mathrm{x} \mathrm{g}$ and removed. Protein concentration was determined by Bradford assay (Bio-Rad Laboratories, Inc., Hercules, CA, USA), and lysate proteins denatured by boiling for $5 \mathrm{~min}$ in reducing SDS-sample buffer. Lysate proteins (15 $\mu \mathrm{g}$ total protein/lane) were separated by $12 \%$ SDS-PAGE and transferred to polyvinylidene fluoride membranes (PVDF, Millipore, Billerica, MA, USA). Membranes were blocked in $7 \%$ bovine serum albumin in TBS and Tween-20 (TBST) for $1 \mathrm{~h}$ at room temperature, and probed overnight at $4^{\circ} \mathrm{C}$ in primary antibody solutions (RAR $\alpha$, RAR $\beta$ and RAR $\gamma$; Abcam, Cambridge, UK; dilution, 1:1,000) [cyclin-dependent kinase inhibitor 1A (p21), proliferating cell nuclear antigen (PCNA), protein kinase B (AKT), phosphorylated (p)-AKT and GAPDH (dilution, 1:500; Santa Cruz Biotechnology, Inc., Dallas, TX, USA) in TBST. They were then washed in TBST 3 times for $5 \mathrm{~min}$, and incubated in TBST solution containing 25\% (v/v) non-fat dry milk powder and goat anti-rabbit (cat. no., 31430) and goat anti-mouse (cat. no. 31460) secondary antibodies (1:300) conjugated to horseradish peroxidase (Invitrogen; Thermo Fisher Scientific, Inc.) for $1 \mathrm{~h}$ at room temperature. Finally, the membranes were washed in TBST 3 time for $5 \mathrm{~min}$, and bands imaged using Western Lightning Plus-ECL (PerkinElmer, Inc., Waltham, MA, USA) and HyBlot ES autoradiography film (Denville Scientific Inc.). The band intensities for western blot analysis were quantified using Image J 1.48 software (National Institutes of Health, Bethesda, MD, USA) and normalized to GAPDH. All experiments were performed in triplicate.

Hematoxylin and eosin staining $(H \& E)$ and immunohistochemistry (IHC). LSCC and the adjacent noncancerous specimens were fixed in $10 \%$ formalin for $24 \mathrm{~h}$ at room temperature, paraffin embedded and cut into $3-\mu \mathrm{m}$ thick sections for $\mathrm{H} \& \mathrm{E}$ or IHC. The H\&E staining were performed according to manufacturer's protocol of H\&E Staining kit (Beijing Solarbio
Science \& Technology Co., Ltd., Beijing, China). IHC staining using anti-RAR $\alpha$ antibody (1:300; cat. no. ab117728; Abcam) was detected using the EliVisionTM Plus kit (Fuzhou Maixin Biotech Co., Ltd., Fuzhou, China) according to the manufacturer's protocol. PBS without primary antibody was used as the negative control. The IHC staining result was evaluated based on the proportion of stained tumor cells. RAR $\alpha$-positive tumor cells were counted in 10 randomly selected high power fields under a light microscope (Olympus BH-2; Olympus Corporation) at a magnification of $\mathrm{x} 400$ and was evaluated according to the following criteria: $<5 \%$ was defined as -; $5-25 \%$ as $+; 25-50 \%$ as $++;>50 \%$ as +++ . Expression of RAR $\alpha$ protein was categorized as low (- to + ) or high $(++$ to +++$)$.

Cell cycle analysis. To detect the cell cycle distribution, cells were collected following transfection with siRAR $\alpha$ or siCtrl at $37^{\circ} \mathrm{C}$ for $48 \mathrm{~h}$ and washed twice with ice cold PBS, and then fixed in ice-cold $70 \%$ ethanol at $4^{\circ} \mathrm{C}$ overnight. Following centrifugation for $5 \mathrm{~min}$ at $4^{\circ} \mathrm{C}$ and $2,000 \mathrm{x} \mathrm{g}$, the cells were resuspended in $100 \mu \mathrm{g} / \mathrm{ml}$ RNase A at $37^{\circ} \mathrm{C}$ for $30 \mathrm{~min}$ and subsequently stained with $50 \mu \mathrm{g} / \mathrm{ml}$ propidium iodide (Sangon Biotech Co., Ltd., Shanghai, China) at $4^{\circ} \mathrm{C}$ for $30 \mathrm{~min}$ in the dark. The cells were analyzed using a FACScan flow cytometer (BD Biosciences, Franklin Lakes, NJ, USA) at $488 \mathrm{~nm}$ and the data was analyzed using ModFit 3.3 (Verity Software House, Topsham, ME, USA) software.

Statistical analysis. Data analysis was conducted using SPSS software (version 16.0; SPSS, Inc., Chicago, IL, USA). Continuous data was expressed as the mean \pm the standard error of the mean and analyzed using one-way analysis of variance with a Tukey's post hoc test, whilst $\chi^{2}$ or Fisher's exact tests were used to examine the association between RAR $\alpha$ and the clinicopathological parameters of LSCC. $\mathrm{P}<0.05$ was considered to indicate a statistically significant difference.

\section{Results}

$R A R \alpha$ was elevated in laryngeal carcinoma tissues. IHC was performed to detect the expression levels of RAR $\alpha$ in LSCC tissues and the adjacent noncancerous tissues. As presented in Fig. 1, the expression of RAR $\alpha$ in the paired adjacent paratumor tissues was weak or negative, but was strong in the LSCC tissues. In addition, RAR $\alpha$ exhibited high expression levels in 

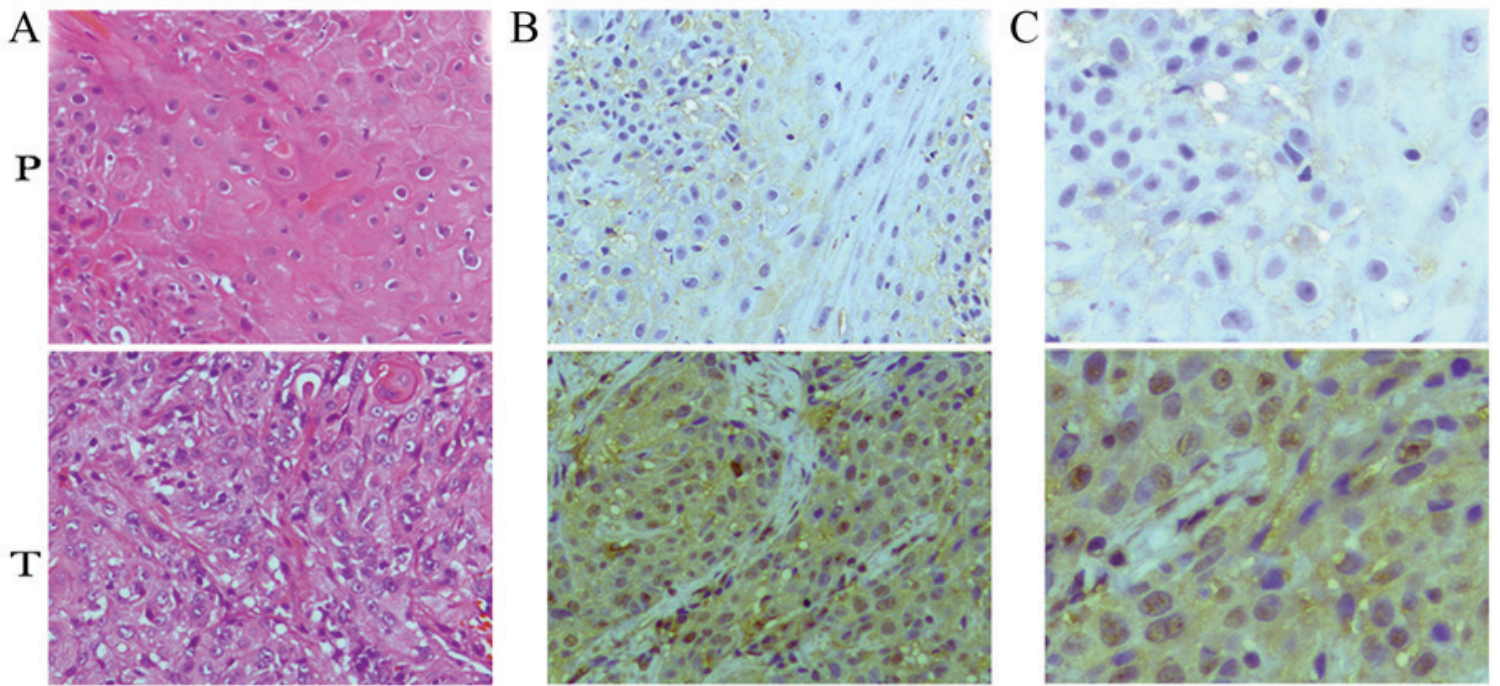

Figure 1. Expression of RAR $\alpha$ in laryngeal squamous cell carcinoma tissues and paired paratumor tissues. (A) Representative images of H\&E staining for $\mathrm{T}$ and $\mathrm{P}$ tissues at magnification, x100. (B) Representative images of IHC staining for RAR $\alpha$ protein in T and P tissues at magnification, $\mathrm{x} 100$. (C) Representative images of IHC staining for RAR $\alpha$ protein in T and P tissues at magnification, $\mathrm{x} 400$. RAR $\alpha$, retinoic acid receptor- $\alpha$; H\&E, hematoxylin and eosin staining; IHC, immunohistochemical staining; T, tumor; P, paratumor.

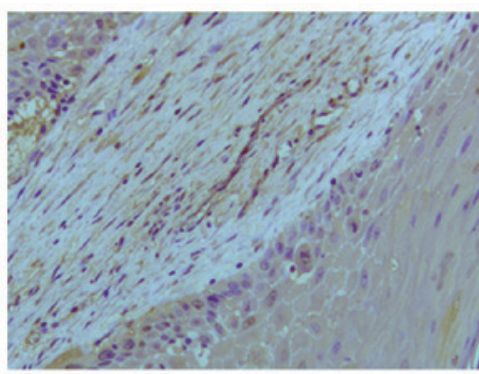

$\mathrm{H}$

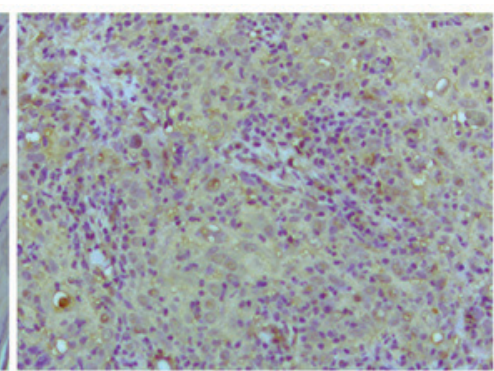

M

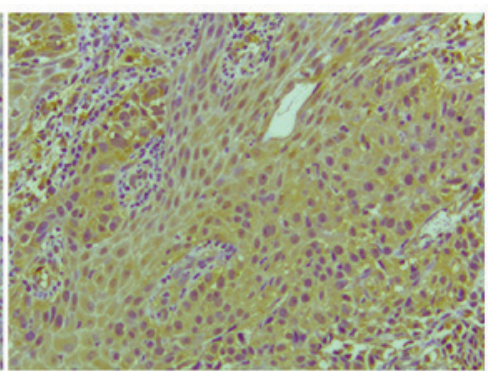

L

Figure 2. Expression of RAR $\alpha$ protein in tumor tissues of different pathologic differentiation. Representative images of immunohistochemical staining for $\mathrm{RAR} \alpha$ protein in $\mathrm{L}, \mathrm{M}$ and $\mathrm{H}$ laryngeal squamous cell carcinoma tissues at magnification, $\mathrm{x} 100$. RAR $\alpha$, retinoic acid receptor- $\alpha ; \mathrm{L}$, low; $\mathrm{M}$, moderate; $\mathrm{H}$, high .

the cytoplasm of cancer cells, with comparatively low expression levels in the nucleus. Furthermore, in order to compare the expression level of RAR $\alpha$ protein in LSCC tissues and the adjacent noncancerous tissues, the expression level was classified into two groups (low expression, - to +; high expression, ++ to +++$)$, which were presented in Table III. The rate of high expression in LSCC tissues was $78.1 \%$, and the rate of high expression in paired adjacent paratumor tissues was $6.3 \%$. The $\chi^{2}$ test statistics demonstrated that the expression of RAR $\alpha$ was significantly higher in LSCC tissues compared with adjacent tissues $(\mathrm{P}<0.05)$.

The clinical significance of RAR overexpression in laryngeal carcinoma. The association between RAR $\alpha$ and the clinicopathological characteristics of LSCC was further analyzed. There was no significant association between RAR $\alpha$ expression and age, sex, TNM stage or clinical stage $(\mathrm{P}>0.05)$. However, high RAR $\alpha$ expression was significantly associated with advanced pathological differentiation $(\mathrm{P}<0.05)$. As presented in Fig. 2, the expression levels of RAR protein in poorly differentiated LSCC tissues was visibly higher than that in moderately differentiated and highly differentiated LSCC tissues. The results of the present study indicate that
Table III. Expression of RAR $\alpha$ in LSCC and paired adjacent paratumor tissues.

\begin{tabular}{lrcr}
\hline & \multicolumn{3}{c}{ RAR $\alpha$ expression } \\
\cline { 2 - 4 } Tissues & Low & High & P-value \\
\hline Paratumor $(\mathrm{N}=32)$ & 30 & 2 & $<0.0001$ \\
LSCC $(\mathrm{N}=32)$ & 7 & 25 &
\end{tabular}

RAR $\alpha$, retinoic acid receptor- $\alpha$; LSCC, laryngeal squamous cell carcinoma.

RAR $\alpha$ may be involved in the regulation of the differentiation of LSCC cells.

Downregulation of RAR $\alpha$ inhibited laryngeal carcinoma cell proliferation in vitro. To assess the effect of downregulating RAR $\alpha$ on the proliferation of LSCC cells, the expression of RAR $\alpha$ was knocked down using siRAR $\alpha$, and the control group siCtrl was transfected with non-specific fragments. The specificity of siRNA was confirmed by the observation that the expression 

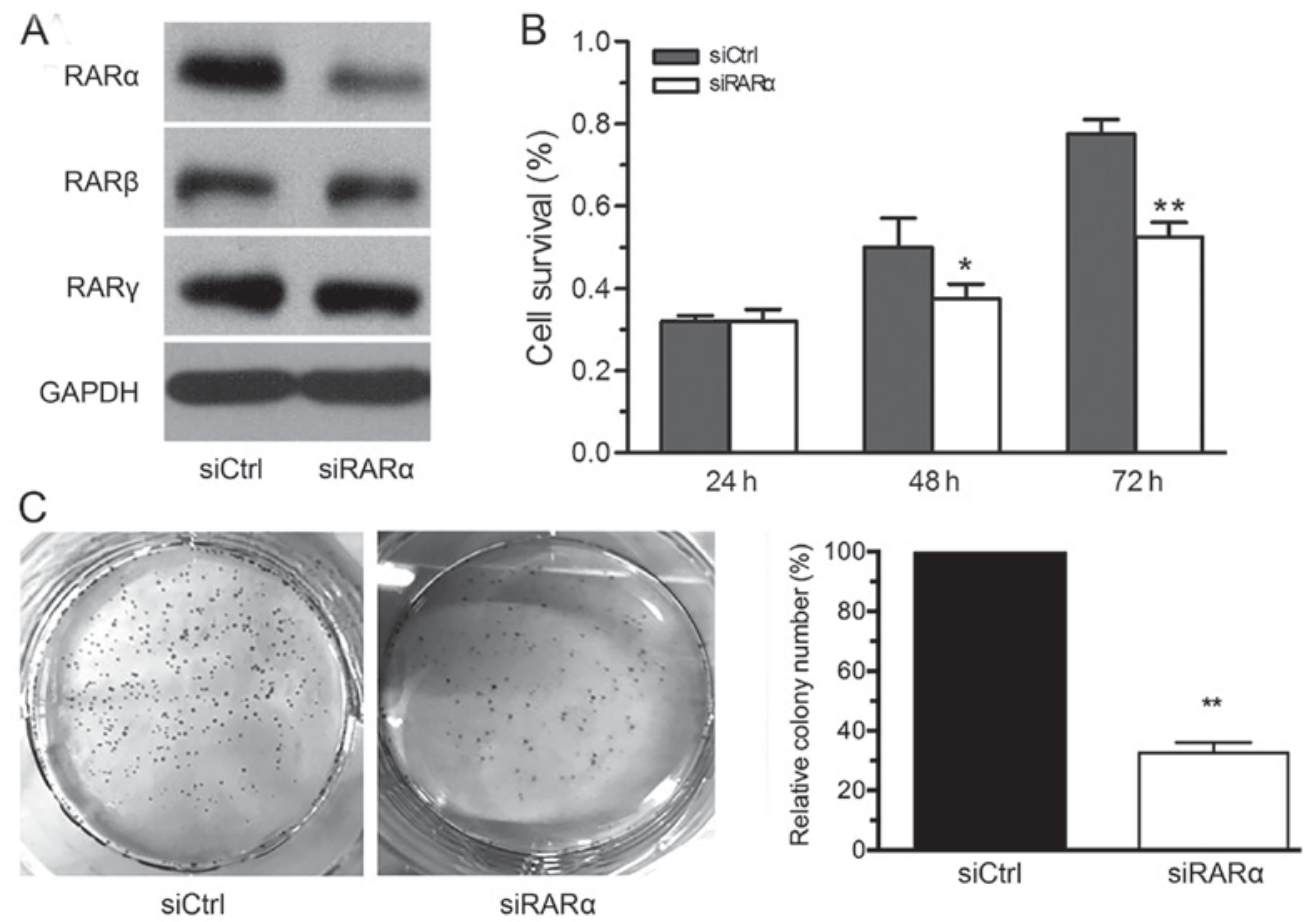

Figure 3. Effect of RAR $\alpha$ knockdown on the proliferation of laryngeal squamous cell carcinoma cells. (A) RAR $\alpha$, RAR $\beta$, and RAR $\gamma$ protein expression was detected using western blotting with GAPDH as the loading control. (B) MTT assays to analyze cell proliferation were performed in AMC-HN-8 cells following transfection with siRAR $\alpha$ or siCtrl for $24 \mathrm{~h}$. (C) Colony formation assays were performed in siCtrl and siRAR $\alpha$ cells. The mean number of foci formed by siCtrl-AMC-HN-8 cells was normalized to $100 \%$, whilst all other colonies were compared with it. " $\mathrm{P}<0.05$ and ${ }^{* *} \mathrm{P}<0.01$ vs. control group. RAR $\alpha$, retinoic acid receptor- $\alpha$; siRAR $\alpha$, RAR $\alpha$-specific small interfering RNA; siCtrl, small interfering RNA negative control.
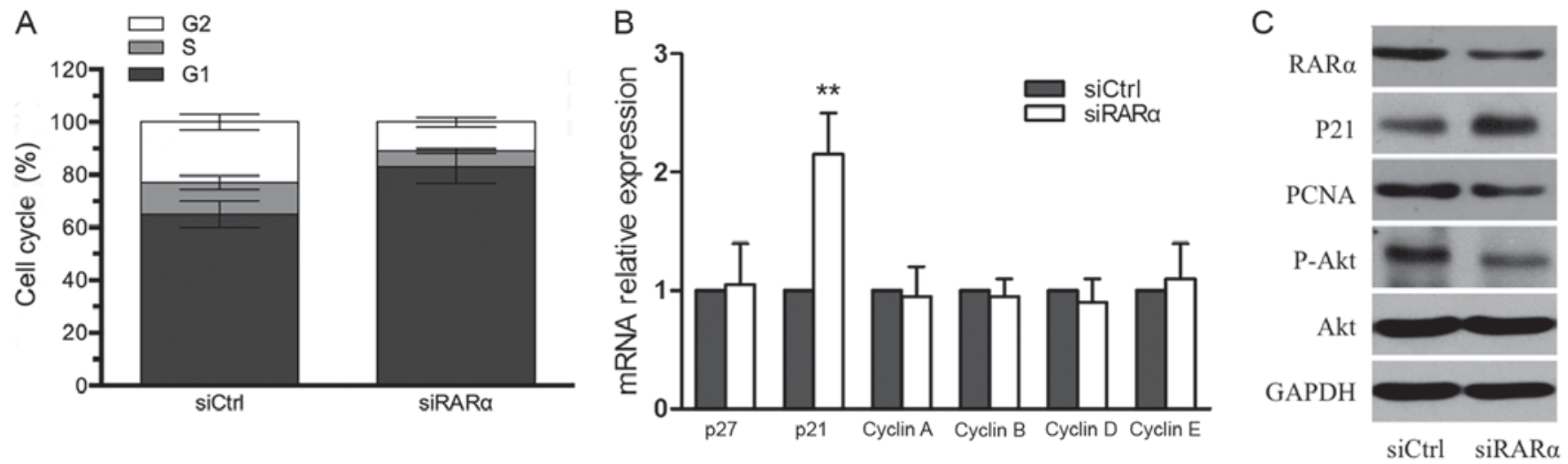

Figure 4. Effect of RAR $\alpha$ knockdown on the cell cycle of AMC-HN-8 cells. (A) Flow cytometry analysis revealed that RAR $\alpha$ knockdown increased the proportion of cells in G0/G1 phase and decreased the number in the G2 phase, compared with the control group. (B) The mRNA expression of several cell cycle associated genes were assessed using reverse transcription-quantitative polymerase chain reaction, following transfection with siRAR $\alpha$ or siCtrl for $24 \mathrm{~h}$. (C) The protein expression of RAR $\alpha$, p21, PCNA, p-AKT and AKT in siCtrl and siRAR $\alpha$-AMC-HN-8 cells were detected using western blotting analysis. ${ }^{* *} \mathrm{P}<0.01$ vs. control group. RAR $\alpha$, retinoic acid receptor- $\alpha$; siRAR $\alpha$, RAR $\alpha$-specific small interfering RNA; siCtrl, small interfering RNA negative control; p21, cyclin dependent kinase inhibitor 1A; PCNA, proliferating cell nuclear antigen; AKT, protein kinase B; p-, phosphorylated.

of RAR $\alpha$, but not RAR $\beta$ or RAR $\gamma$, was downregulated using siRAR $\alpha$ (Fig. 3A). The results from the MTT assay revealed that the proliferation of siRAR $\alpha$-AMC-HN- 8 cells were significantly inhibited from $48 \mathrm{~h}$ following transfection, compared with the siCtrl-AMC-HN-8 cells (Fig. 3B). Furthermore, the downregulation of RAR $\alpha$ significantly decreased the forming foci of AMC-HN-8 cells (Fig. 3C). This data indicated that the downregulation of RAR $\alpha$ inhibited the growth of LSCC cells.

Downregulation of RAR $\alpha$ induced laryngeal carcinoma cell cycle arrest via inhibition of the protein kinase $B(A K T)$ signaling pathway. The development of LSCC is associated with disorder of the cell cycle (16). Therefore, flow cytometry was performed to evaluate the effect of RAR $\alpha$ downregulation on the cell cycle distribution of LSCC cells. The results demonstrated that the down-regulation of RAR $\alpha$ in AMC-HN-8 cells reduced the proportion of cells in the $\mathrm{S}$ and $\mathrm{G} 2 / \mathrm{M}$ phases, and a higher number of cells were arrested in the G0/G1 phase compared with cells in the control group (Fig. 4A). Furthermore, RT-qPCR was performed to detect the mRNA expression of cell cycle associated genes. As presented in Fig. 4B, the expression levels of P21 mRNA in the siRAR $\alpha-A M C-H N-8$ 
cells were $>2 \mathrm{x}$ higher than those of the siCtrl cells, but the mRNA expression of p27, cyclin A, cyclin B, cyclin D, cyclin E was not significantly altered. Furthermore, the results from the western blot analysis confirmed the upregulation of the P21 protein in siRAR $\alpha$-AMC-HN-8 cells (Fig. 4C), which may be associated with the inhibition of the AKT signaling pathway. Thus, this data indicated that the downregulation of RAR $\alpha$ resulted in P21 upregulation and induced G1 phase arrest via inhibition of the AKT signaling pathway.

\section{Discussion}

Laryngeal carcinoma is one of the most aggressive malignant tumors out of all head and neck squamous cell carcinoma, and generally has a poor prognosis (2). The survival time of laryngeal cancer has not increased, despite substantial progress in the developments of surgery and radiotherapy $(3,17)$. Revealing the molecular mechanism underlying the development of LSCC is important for early diagnosis and targeted therapy. The development of LSCC is a complex process which is associated with changeable expression of multiple genes (18). Here, it was revealed that RAR $\alpha$ was elevated in the LSCC tissues and was associated with poor pathological differentiation. Knockdown of RAR $\alpha$ significantly inhibited the proliferation of LSCC cells through the induction of cell cycle arrest.

RAR $\alpha$, regarded as an important member of the retinoic acid receptor family, is involved in the regulation of cell differentiation, proliferation, apoptosis and metabolism. Accumulating evidence has indicated that RAR $\alpha$ serves an important function in the development of malignant tumors. Notably, the functions of RAR $\alpha$ in the development of tumors is dependent on the origin and the microenvironment of tumor cells. RAR $\alpha$ served as a tumor suppressor gene in the development of gastric cancer, non-small cell lung cancer, melanoma tumor and prostate cancer. However, RAR $\alpha$ may also serve as an oncogene in the development of hepatocellular carcinoma, leukemia and breast cancer. In the present study, it was identified that the expression of RAR $\alpha$ in LSCC tissues was significantly higher than that in adjacent noncancerous tissues, suggesting that RAR $\alpha$ may serve as an oncogene, participating in the process of the development of LSCC. Further analysis revealed that overexpression of $\operatorname{RAR} \alpha$ was associated with poor pathologic differentiation. Despite the small sample size of the present study, it was indicated that RAR $\alpha$ may be involved in the regulation of LSCC cell differentiation.

Rapid proliferation, resistance to apoptosis, indefinite reproduction, angiogenesis, invasion and metastasis are the main features in the development of a tumor (19). These are also the biological functions of various types of tumor oncogenes and suppressor genes involved in the development of malignant tumors. In the present study, the downregulation of RAR $\alpha$ significantly inhibited the proliferation of AMC-HN-8 cells through inducing cell cycle arrest. It was indicated that the overexpression of RAR $\alpha$ served an important function in the development of LSCC. Consistent with the present study, previous studies have reported that RAR $\alpha$ was also involved in the regulation of the cell cycle in breast cancer (13). Retinoic acid, a ligand of RAR $\alpha$, inhibited the growth of breast cancer cells through the induction of cell cycle arrest at the G1 phase and cell apoptosis (13). The mechanism of $\operatorname{RAR} \alpha$ in the regulation of the development of LSCC is the focus of a number of studies; it has been reported that there are genomic and non-genomic influences (20). During genomic regulation, the conformation of RAR $\alpha$ changes and recruits a coactivator protein once it is combined with its ligand. The complex forms the retinoic acid response element in the promoter region of the target gene, and then activates the transcription of target genes, resulting in the promotion of cell differentiation, apoptosis and other biological processes (20). In previous years, there was a greater focus on the non-genomic regulation of RAR $\alpha$. Previous studies have identified that RAR $\alpha$ may regulate the phosphoinositide 3-kinase, AKT, c-Jun N-terminal kinase, mitogen-activated protein kinase 14 and protein kinase $\mathrm{C}$ signaling pathways following abnormal translocation into the cytoplasm $(10,21-23)$. The present study identified that the overexpression of RAR $\alpha$ was mainly located in the cytoplasm of LSCC cells and its downregulation significantly inhibited the activation of the AKT signaling pathway. Therefore, it was speculated that $\mathrm{RAR} \alpha$ promoted the development of LSCC through non-genomic transcriptional regulation.

Altogether, the present study has demonstrated that RAR $\alpha$ expression was significantly elevated in patients with LSCC, and the downregulation of RAR $\alpha$ induced cell cycle arrest and inhibited the proliferation of LSCC cells via the inhibition of the AKT signaling pathway. The present study may offer a potential molecular basis for the further development of RAR $\alpha$ as a novel therapeutic target for patients with LSCC.

\section{Acknowledgements}

The present study was supported by the Youth Foundation of the Fujian Health Department, Fujian, China (grant no. 2013-2-83), the Project of Young and Middle-Aged Backbone Talent Cultivation, Fujian, China (grant no. 2013-ZQN-JC-32) and the Science and Technology Bureau of Xiamen, China (grant no. 3502Z20144004). The present study was also supported by the National Nature Science Foundation of China (grant no. 81572394).

\section{References}

1. Jemal A, Bray F, Center MM, Ferlay J, Ward E and Forman D: Global cancer statistics. CA Cancer J Clin 61: 69-90, 2011.

2. Marur S and Forastiere AA: Head and neck squamous cell carcinoma: Update on epidemiology, diagnosis, and treatment. Mayo Clin Proc 91: 386-396, 2016.

3. Belcher R, Hayes K, Fedewa S and Chen AY: Current treatment of head and neck squamous cell cancer. J Surg Oncol 110: 551-574, 2014.

4. di Masi A, Leboffe L, De Marinis E, Pagano F, Cicconi L, Rochette-Egly C, Lo-Coco F, Ascenzi P and Nervi C: Retinoic acid receptors: From molecular mechanisms to cancer therapy. Mol Aspects Med 41: 1-115, 2015.

5. Altucci L, Leibowitz MD, Ogilvie KM, de Lera AR and Gronemeyer H: RAR and RXR modulation in cancer and metabolic disease. Nat Rev Drug Discov 6: 793-810, 2007.

6. Shiohira H, Kitaoka A, Shirasawa H, Enjoji M and Nakashima M: Am80 induces neuronal differentiation in a human neuroblastoma NH-12 cell line. Int J Mol Med 26: 393-399, 2010.

7. Casey NP and Woods GM: Anti-PML-RAR $\alpha$ shRNA sensitises promyelocytic leukaemia cells to all-trans retinoic acid. J RNAi Gene Silencing 8: 464-469, 2012.

8. Singh AT, Evens AM, Anderson RJ, Beckstead JA, Sankar N, Sassano A, Bhalla S, Yang S, Platanias LC, Forte TM, et al: All trans retinoic acid nanodisks enhance retinoic acid receptor mediated apoptosis and cell cycle arrest in mantle cell lymphoma. Br J Haematol 150: 158-169, 2010. 
9. Wu Q, Lin XF, Ye XF, Zhang B, Xie Z and Su WJ: Ubiquitinated or sumoylated retinoic acid receptor alpha determines its characteristic and interacting model with retinoid $\mathrm{X}$ receptor alpha in gastric and breast cancer cells. J Mol Endocrinol 32: 595-613, 2004.

10. Hoshikawa Y, Kanki K, Ashla AA, Arakaki Y, Azumi J, Yasui T, Tezuka Y, Matsumi Y, Tsuchiya H, Kurimasa A, et al: c-Jun $\mathrm{N}$-terminal kinase activation by oxidative stress suppresses retinoid signaling through proteasomal degradation of retinoic acid receptor $\alpha$ protein in hepatic cells. Cancer Sci 102: 934-941, 2011.

11. Sano K, Takayama T, Murakami K, Saiki I and Makuuchi M: Overexpression of retinoic acid receptor alpha in hepatocellular carcinoma. Clin Cancer Res 9: 3679-3683, 2003.

12. Schneider SM, Offterdinger M, Huber $\mathrm{H}$ and Grunt TW: Activation of retinoic acid receptor alpha is sufficient for full induction of retinoid responses in SK-BR-3 and T47D human breast cancer cells. Cancer Res 60: 5479-5487, 2000.

13. Lu M, Mira-y-Lopez R, Nakajo S, Nakaya K and Jing Y: Expression of estrogen receptor alpha, retinoic acid receptor alpha and cellular retinoic acid binding protein II genes is coordinately regulated in human breast cancer cells. Oncogene 24: 4362-4369, 2005.

14. Gyftopoulos K, Perimenis P, Sotiropoulou-Bonikou G, Sakellaropoulos G, Varakis I and Barbalias GA: Immunohistochemical detection of retinoic acid receptor-alpha in prostate carcinoma: Correlation with proliferative activity and tumor grade. Int Urol Nephrol 32: 263-269, 2000.
15. Livak KJ and Schmittgen TD: Analysis of relative gene expression data using real-time quantitative PCR and the 2(-Delta Delta C(T)) method. Methods 25: 402-408, 2001.

16. Pignataro L, Sambataro G, Pagani D and Pruneri G Clinico-prognostic value of D-type cyclins and p27 in laryngeal cancer patients: A review. Acta Otorhinolaryngol Ital 25: 75-85, 2005.

17. Li P, Hu W, Zhu Y and Liu J: Treatment and predictive factors in patients with recurrent laryngeal carcinoma: A retrospective study. Oncol Lett 10: 3145-3152, 2015.

18. Ni RS, Shen X, Qian X, Yu C, Wu H and Gao X: Detection of differentially expressed genes and association with clinicopathological features in laryngeal squamous cell carcinoma. Oncol Lett 4: 1354-1360, 2012

19. Hanahan D and Weinberg RA: Hallmarks of cancer: The next generation. Cell 144: 646-674, 2011.

20. Hart SM: Modulation of nuclear receptor dependent transcription. Biol Res 35: 295-303, 2002

21. Srinivas H, Xia D, Moore NL, Uray IP, Kim H, Ma L, Weigel NL, Brown PH and Kurie JM: Akt phosphorylates and suppresses the transactivation of retinoic acid receptor alpha. Biochem J 395: 653-662, 2006

22. Boskovic G, Desai D and Niles RM: Regulation of retinoic acid receptor alpha by protein kinase $\mathrm{C}$ in B16 mouse melanoma cells. J Biol Chem 277: 26113-26119, 2002.

23. Piskunov A and Rochette-Egly C: A retinoic acid receptor RAR $\alpha$ pool present in membrane lipid rafts forms complexes with $G$ protein $\alpha \mathrm{Q}$ to activate p38MAPK. Oncogene 31: 3333-3345, 2012. 